\title{
Polyaniline/palladium nanohybrids for moisture and hydrogen detection
}

CrossMark

\author{
Chanaka Sandaruwan ${ }^{1,2^{*}}$ D, H. M. P. C. K. Herath², T. S. E. F. Karunarathne' , S. P. Ratnayake ', G. A. J. Amaratunga ${ }^{1,3}$ \\ and D. P. Dissanayake ${ }^{2}$
}

\begin{abstract}
Palladium nanoparticles display fascinating electronic, optical and catalytic properties, thus they can be used for various applications such as sensor fabrication. Conducting polymers such as polyaniline have also been widely used in sensor technology due to its cost effectiveness, versatility, and ease of synthesis. In this research, attention was given to unify the exceptional properties of these two materials and construct palladium nanoparticle coated polyaniline films to detect hydrogen and moisture. Electrochemical polymerization of aniline was carried out on gold sputtered epoxy resin boards. Polyaniline film was generated across a gap of $0.2 \mathrm{~mm}$ created by a scratch made on the gold coating prior to electrochemical polymerization. A palladium nanoparticle dispersion was prepared using sonochemical reduction method and coated on to polyaniline film using drop-drying technique. Polyaniline only films were also fabricated for comparative analysis. Sensitivity of films towards humidity and hydrogen was evaluated using impedance spectroscopy in the presence of the respective species. According to the results, polyaniline films exhibited an impedance drop in the presence of humidity and the response was significantly improved once palladium nanoparticles were incorporated. Interestingly, polyaniline only films did not respond to hydrogen. Nevertheless, palladium nanoparticle coated polyaniline films exhibited remarkable response towards hydrogen.
\end{abstract}

Keywords: Conductive polymers, Nanoparticles, Sensors, Impedance spectroscopy

\section{Introduction}

Hydrogen gas plays a significant role in green energy technology as it is known as the "common fuel of the future". Being a clean, renewable and efficient fuel, it holds a commendable usability as a green energy source $[1,2]$. Currently, it is utilized in many industries such as petroleum refining and metallurgical engineering [2-7]. Hydrogen has distinctive properties such as low minimum ignition energy, wide flammable range and detonation sensitivity. It is a colorless, odorless and a tasteless gas. Due to these reasons, detection of hydrogen is highly important [1,3]. Different types of sensors can be used to detect hydrogen qualitatively or quantitatively. These sensors can be categorized as catalytic, thermal, electrochemical, mechanical, optical, acoustic and conductive sensors $[3,8,9]$. In this regard, palladium nanoparticles

\footnotetext{
*Correspondence: chanakas@slintec.lk

1 Sri Lanka Institute of Nanotechnology (SLINTEC), Homagama, Sri Lanka
}

Full list of author information is available at the end of the article
(Pd NPs) have been used extensively to sense hydrogen [3, 7-16], due to its special properties at the nanoscale and its affinity towards $\mathrm{H}_{2}[10,11,17-31]$. During the sensing of $\mathrm{H}_{2}$, adsorption of $\mathrm{H}_{2}$ on to the surface of the Pd NPs causes the $\alpha$-phase (conductive) of $\mathrm{PdH}_{\mathrm{x}}$ to convert to the $\beta$-phase (less-conductive) which leads to the detection of hydrogen [13-15].

Humidity which is simply the water vapor in air can be expressed in terms of absolute humidity (ppm), dew/ frost point (D/F PT) and relative humidity (RH) [32, 33]. Humidity plays a significant role in automated industrial processes such as pharmaceutical production, food processing, electronics fabrication and agriculture [32, 34-37] hence, it is essential to monitor, detect and control such parameter [33]. Humidity can be measured using different types of sensors which are categorized as capacitive, resistive and thermal conductive sensors [32-35, 38-49], which are primarily based on the measurement of RH. Humidity sensing action of polyaniline (PAni) is attributed to the changes of resistance due to 
the adsorption of water molecules to its surface. Exposure to water vapor protonates PAni (acid-base reaction) via electron hopping assisted by a proton transfer mechanism and shows increased conductivity [43].

Detection of both hydrogen/humidity together is quite a challenge as the sensing system should encompass high sensitivity, wide dynamic range, good stability and quick response capability [3, 8, 50-52]. Even though researchers have used palladium nanoparticles for the detection of hydrogen and polyaniline conductive polymers for the detection of humidity, a combined system has not been investigated up to date. Hence, in this study, both hydrogen and humidity sensing ability of Pd nanoparticle coated PAni thin film have been investigated.

\section{Materials and methods Materials}

All chemicals and reagents used in this study were analytical grade and purchased from Sigma-Aldrich, USA. Aniline was double distilled prior to electrochemical polymerization and all other chemicals were used as received. All aqueous solutions were prepared using distilled water.

\section{Preparation of gold sputtered glass-epoxy resin substrate for electrochemical deposition of PAni}

Initially, copper clad boards (1.0-1.5 mm thick) containing an epoxy resin (ER) were cut into $1 \times 4 \mathrm{~cm}$ size chips using a laser cutter. Then, a thin marker pen line $(0.2 \mathrm{~mm})$ was drawn on its longest axes of cemetery on the copper plated side. Resulting chip was then treated with previously prepared $\mathrm{FeCl}_{3} \cdot 6 \mathrm{H}_{2} \mathrm{O}$ solution to remove copper plating on the unmarked area. Etched chip was then treated with acetone and ethanol to remove the pen line which was drawn before and to acquire a thin copper line. This copper line-containing chip was gold sputtered (Hitachi E1010) under a vacuum of approximately $10 \mathrm{~Pa}$ and a discharging current of $10 \mathrm{~mA}$ up to $120 \mathrm{~S}$. A small scratch was made on top of the copper line to remove gold coating to clear the thin copper line. Obtained chip was again treated with previously prepared $\mathrm{FeCl}_{3} \cdot 6 \mathrm{H}_{2} \mathrm{O}$ to remove the thin copper line to obtain two gold electrodes separated by $0.2 \mathrm{~mm}$ gap.

\section{Synthesis of PAni thin film deposited ER for humidity sensing}

Prepared gold sputtered ER containing two separate gold electrodes was then dipped in a solution containing $4.20 \mathrm{~g}$ of double distilled aniline in $100.0 \mathrm{~cm}^{3}$ of $0.5 \mathrm{M} \mathrm{H}_{2} \mathrm{SO}_{4}$. The two gold electrodes were then connected together using a crocodile clip and connected to the positive terminal of the power supply and a voltage of $1.41 \mathrm{~V}$ was applied for $25 \mathrm{~min}$. Another gold sputtered
ER electrode was used as the counter electrode. The solution mixture was stirred at a rate of $100 \mathrm{rpm}$ during the electrochemical polymerization. This procedure generated a thin polyaniline layer between the separated gold electrodes making an electrical contact.

\section{Synthesis of Pd nanoparticle dispersion}

Firstly, $\mathrm{Pd}\left(\mathrm{NO}_{3}\right)_{2}(5.0 \mathrm{~g})$ was dissolved in $50 \mathrm{ml}$ of water. Then, the reaction mixture was prepared by adding $0.2 \mathrm{~g}$ of Poly(vinylpyrrolidone) (PVP, M.W-10,000) into ethylene glycol $(40 \mathrm{ml})$ and mixed for $15 \mathrm{~min}$ [53]. Then $2.0 \mathrm{ml}$ of previously prepared $\mathrm{Pd}\left(\mathrm{NO}_{3}\right)_{2}$ solution $\left(8.7 \times 10^{-4}\right.$ mol) was added to the reaction mixture. Finally, this reaction mixture was subjected to continuous sonochemical irradiation for 120 min using a multiwave ultrasonic generator operating at an amplitude of $20 \mathrm{kHz}$ [53].

\section{Preparation of Pd nanoparticles incorporated PAni thin films (PIPTF)}

Resulted Pd nanoparticle dispersion was drop dried on the surface of PAni thin film using vacuum drying at $50{ }^{\circ} \mathrm{C}$ for $30 \mathrm{~min}$. This was repeated 10 times and resulting chips were subjected to $\mathrm{H}_{2}$ and $\mathrm{H}_{2} \mathrm{O}$ sensing experiments.

For a comparative analysis, Pd nanoparticle dispersion was spin coated on the surface of gold sputtered ER boards.

\section{Morphological studies}

Morphology of resulted chips was examined using scanning electron microscopy (SEM) (HITACHI SU6600) and atomic force microscopy (AFM) (PARK SYSTEMS XE100).

\section{Impedance measurements}

A 5.0 Vpp sinusoidal signal was supplied to the sensors using a function generator (TEKTRONIX 3022B) at different humidity [54] and hydrogen environments $[6,13]$. Moisture traps were used to ensure that hydrogen environments were $100 \%$ moisture free. The output voltage signals were measured using a dual channel digital oscilloscope (TEKTRONIX DPO 2012). The variations in output signals (amplitude and the phase shift) as the signal frequency varied (from $20 \mathrm{~Hz}$ to $25 \mathrm{MHz}$ ) were observed and the impedance was measured.

\section{Results and discussion}

\section{Characterization of gold sputtered ER boards}

Sputtered gold film was characterized using resistance measurements, which was found to be less than $5 \Omega$ between two $10 \mathrm{~mm}$ distance points. Resistivity reached infinity in between two gold electrodes after they were 
separated by a narrow scratch $(0.2 \mathrm{~mm})$ (Fig. $1 \mathrm{~A}, \mathrm{~B})$ and the schematic diagram of the sensor is given in Fig. 1C.

The strong absorption band having a distribution from 3400 to $3500 \mathrm{~cm}^{-1}$ region in the Fourier transform infrared (FT-IR) spectrum of the ER (Fig. 2) strongly suggest the presence of hydroxyl groups on the ER surface. These hydroxyl groups work as potential sites for the adsorption of aniline molecules during the electrochemical polymerization process [54].

\section{Characterization of PAni film deposited ER boards}

The electro-deposition of polyaniline started as a blue colored layer on the surface of the gold sputtered ER board. This is the poly pernigraniline base which is the intermediate protonated form of polyaniline [55]. Later, it becomes green as pernigraniline is converted into the final product, the protonated emeraldine form of polyaniline (Fig. 3A).

In order to deposit a uniform layer of polyaniline, it is important to maintain a low voltage during the deposition $[55,56]$. Optical microscopic images revealed that the resulted two electrodes are connected by the PAni film effectively (Fig. 3B). The thickness of electro-polymerized PAni films was measured using a sensitive thickness gauge and was recorded as $42( \pm 1) \mu \mathrm{m}$.

In order to identify the chemical composition of the deposited PAni film, FT-IR spectra were recorded in the

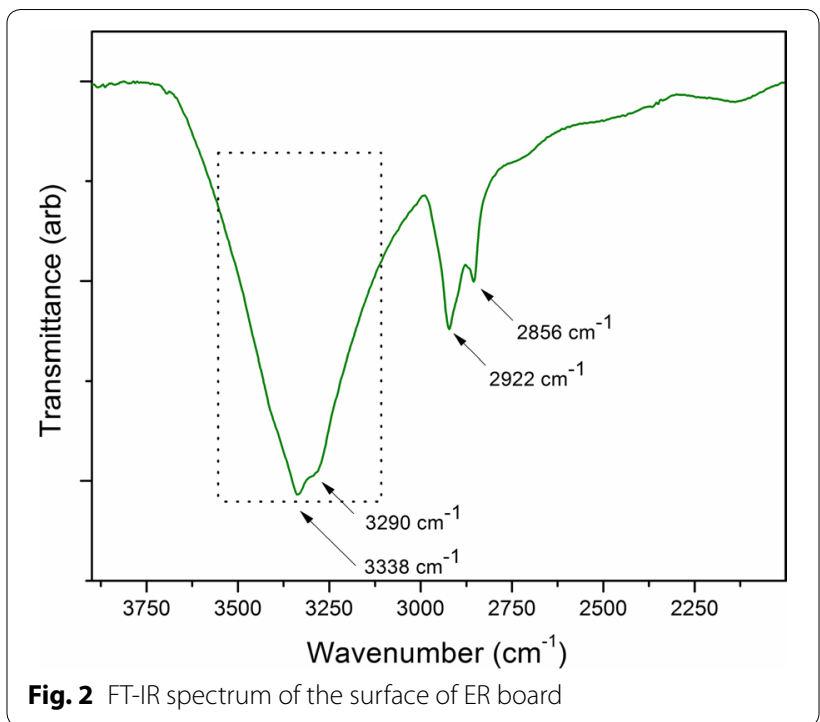

range of $4000-400 \mathrm{~cm}^{-1}$ before (A) and after (B) drying (Fig. 4).

A broad peak around $3400 \mathrm{~cm}^{-1}$ is responsible for the $\mathrm{N}-\mathrm{H}$ stretching of PAni. The peak at $3230 \mathrm{~cm}^{-1}$ accounts for the $\mathrm{OH}$ stretching of water molecules physisorbed to the PAni backbone. A sharp band at $1650 \mathrm{~cm}^{-1}$ in PAni is due to asymmetric stretching and bending modes of water. It can be clearly seen that
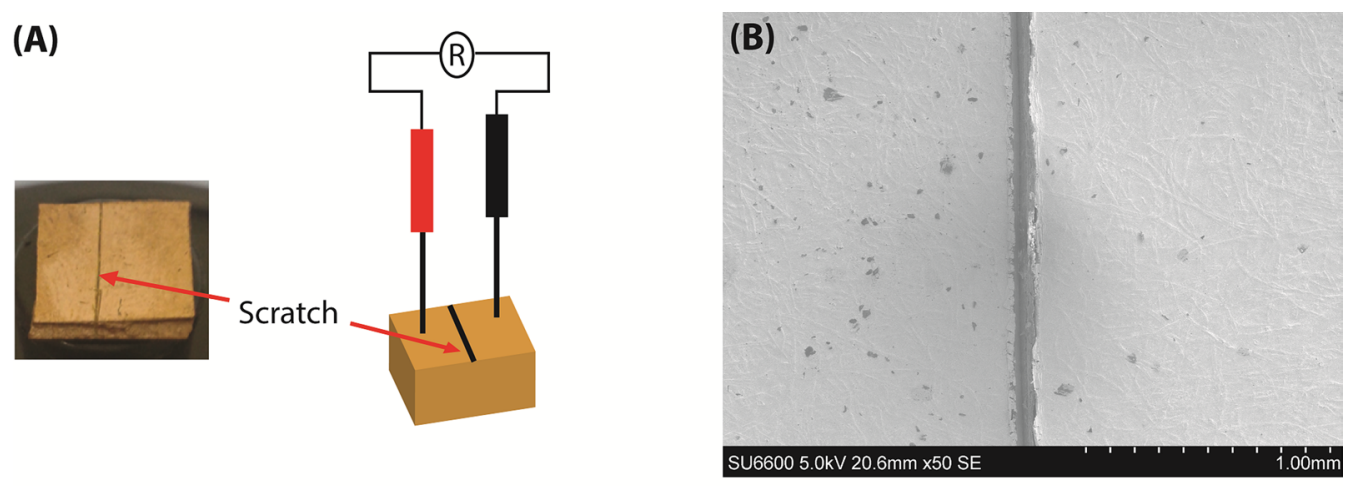

(C)

Surface

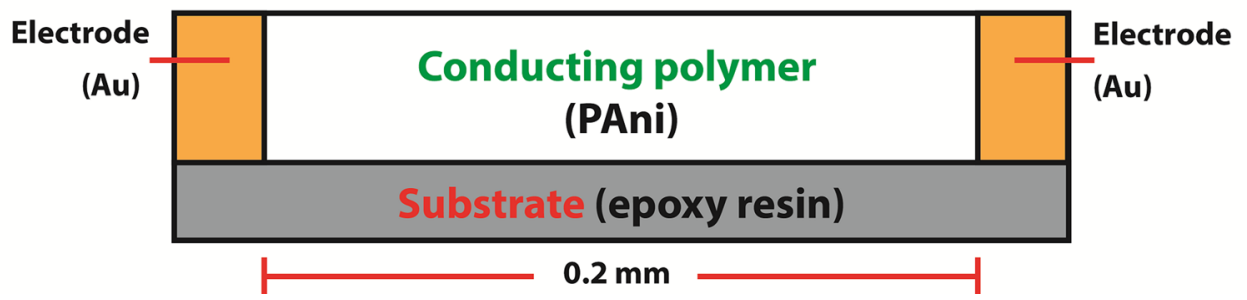

Fig. 1 A Scratched gold sputtered ER boards, B SEM image of the scratched gold sputtered ER boards and $\mathbf{C}$ schematic diagram of the sensor 


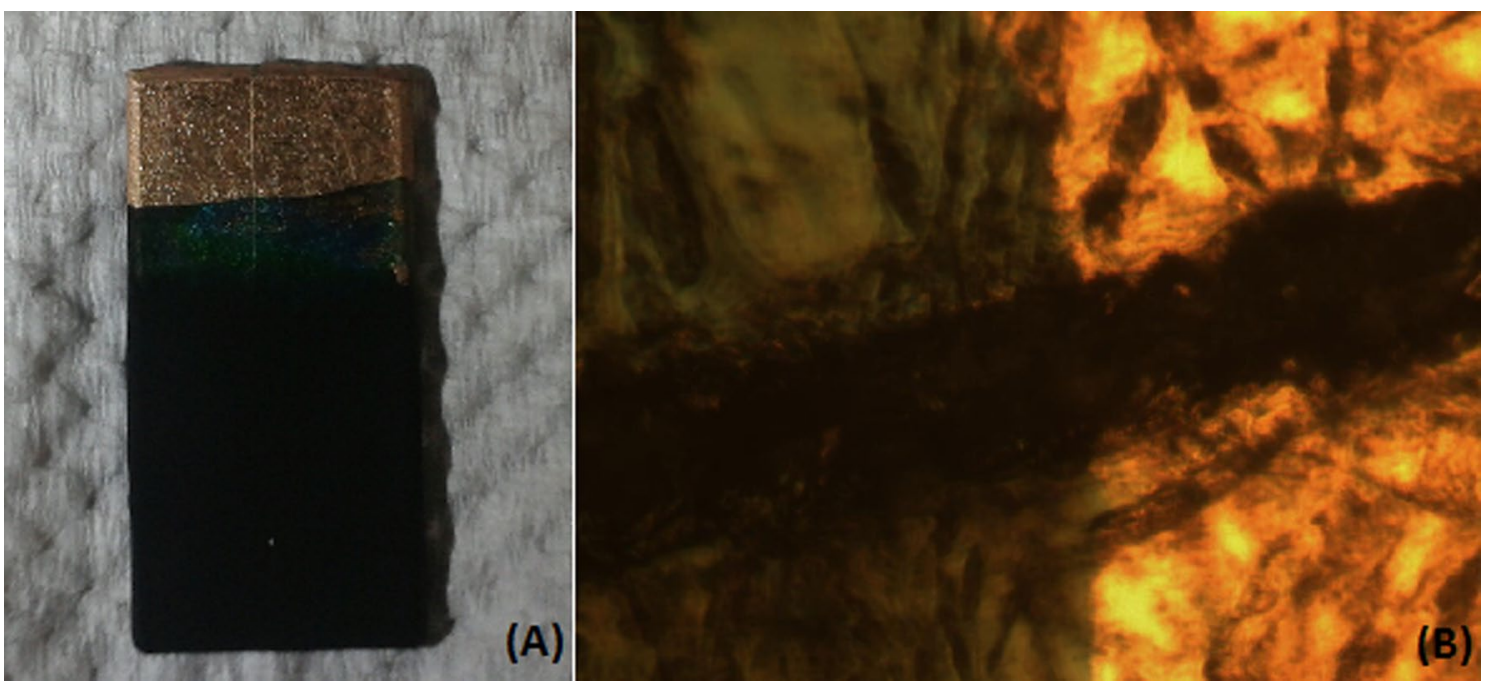

Fig. 3 A PAni film deposited gold sputtered ER board and B optical microscopic image of PAni film deposited gold sputtered ER board

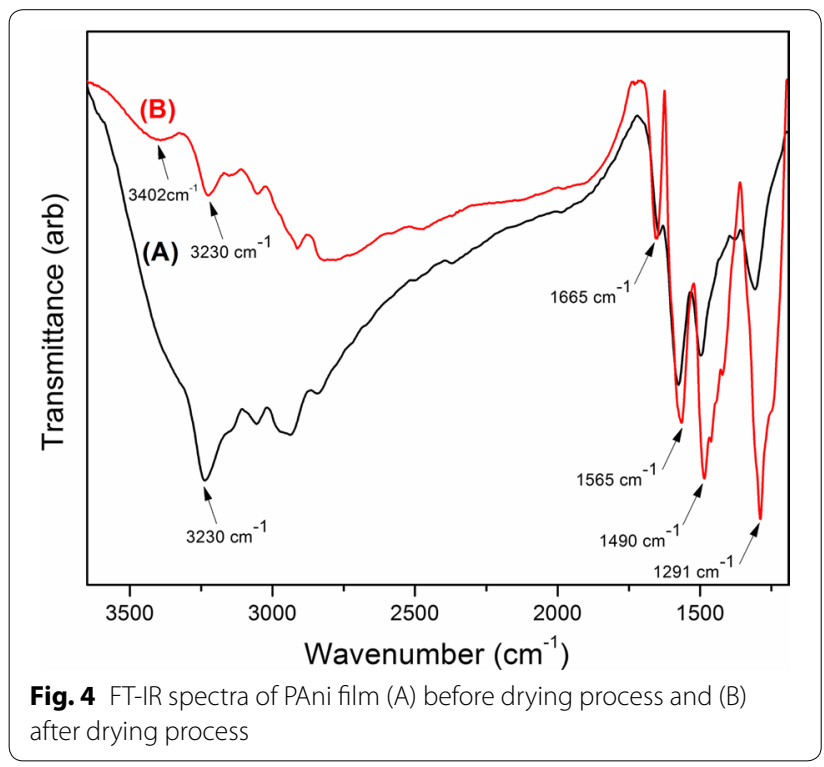

the broadness of the $\mathrm{OH}$ stretching band is reduced after the drying process. The peaks at $1565 \mathrm{~cm}^{-1}$ and $1490 \mathrm{~cm}^{-1}$ are due to the quinoid and benzoid structures of PAni, respectively. Meanwhile, secondary C-N stretching band can be observed around $1290 \mathrm{~cm}^{-1}$ which further confirms the presence of Quinoid and Benzoid structures of PAni [57, 58]. According to the structural analysis, the ratio between quinoid to benzoid was found to be 1 . This clearly indicates the presence of highly doped emeraldine salt form of polyaniline [55].

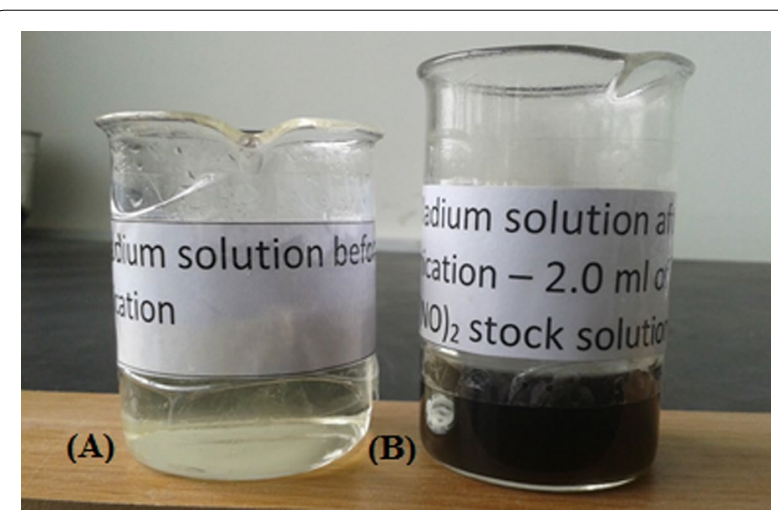

Fig. 5 Appearance of $\mathbf{A}$ the reaction mixture before the sonication process started and $\mathbf{B}$ the reaction mixture after the sonication process is completed

\section{Characterization of Pd nanoparticle dispersion}

The pale yellow color of the $\mathrm{Pd}\left(\mathrm{NO}_{3}\right)_{2}$ mixture was changed into dark brown after ultrasonication (Fig. 5). This observation provided an initial evidence for the formation of Pd nanoparticles during the sonochemical reduction of $\mathrm{Pd}\left(\mathrm{NO}_{3}\right)_{2}$ [53]. Resulted $\mathrm{Pd}$ nanoparticle solution persists over 15 months without any aggregation. The change in $\mathrm{pH}$ of the reaction mixture from 2.97 to 2.62 after the ultrasonication is in good agreement with the literature, confirming the reduction of $\mathrm{Pd}^{2+}$ ions to Pd nanoparticles $[53,59]$.

Pd nanoparticle formation was investigated using UV-Visible spectroscopy in the wavelength range of 250-750 nm. UV absorption of the Pd nanoparticle 
suspension after the sonication was compared with the initial solution containing ethylene glycol, PVP and $\mathrm{Pd}\left(\mathrm{NO}_{3}\right)_{2}$. The UV band around $290 \mathrm{~nm}$ due to the $\mathrm{d}-\mathrm{d}$ transition in the aqua complex $\left[\mathrm{Pd}\left(\mathrm{H}_{2} \mathrm{O}\right)_{4}\right]^{2+}$, disappeared with the formation of Pd nanoparticles [60]. In addition, the spectrum of the ultrasonicated sample

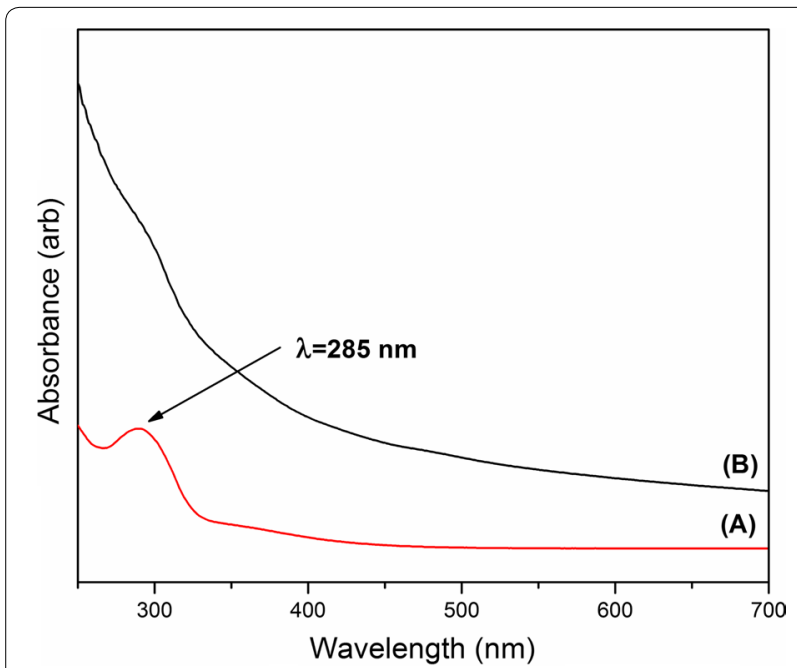

Fig. 6 UV-Visible spectra of (A) starting solution and (B) sample after sonication yields broad continuous absorptions in the UV-visible range which can be assigned to the presence of Pd nanoparticles (Fig. 6) [53].

The average dynamic diameter of Pd-nanoparticles is around $115 \mathrm{~nm}$ (Fig. 7). The polydispersion index (PDI) is 0.179 , which indicates the uniformity of the Pd nanoparticle dispersion.

However, SEM analysis revealed that the particle size varied from 20 to $40 \mathrm{~nm}$ (Fig. 8). The discrepancy between SEM and dynamic light scattering based particle size measurements could be attributed to the formation of polymermetal cluster complexes by the interaction of protective polymers and Pd nanoparticles. The particle size analyzer identifies polymer protected nanoparticle aggregates as a single unit instead of separate entities. SEM images support the formation of bulky polymer-metal complexes which (nanoparticle-buried polymer matrix) can be clearly observed [61]. In addition, a uniform distribution of the Pd nanoparticles in the polymer matrix also can be observed in the SEM images. Energy dispersive X-ray (EDX) analysis was conducted to verify the presence and to quantify the amount of Pd present in the Pd nanoparticle dispersion. Results indicated that $3.74 \%$ by weight of Pd is present in the matrix (Fig. 8).

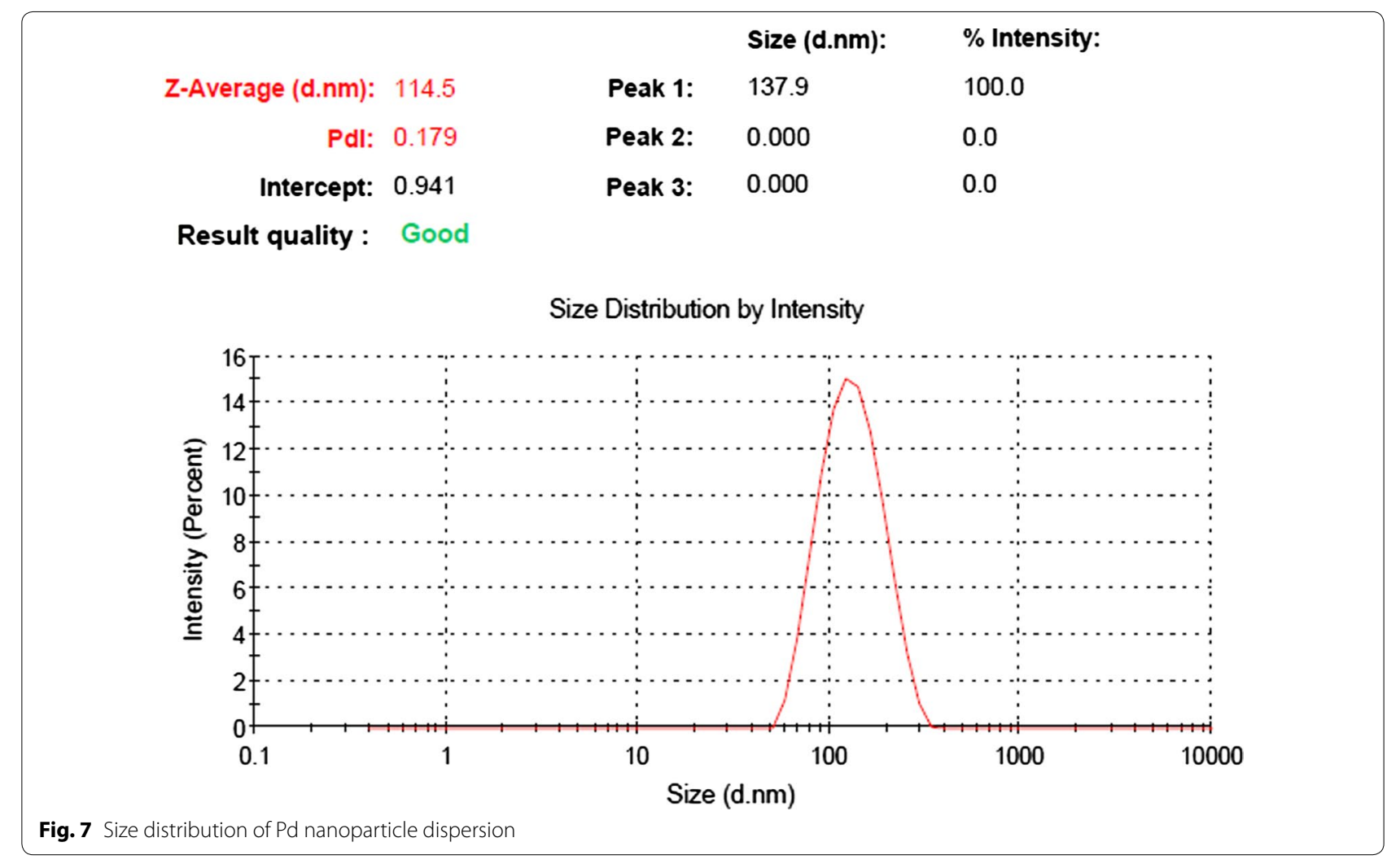



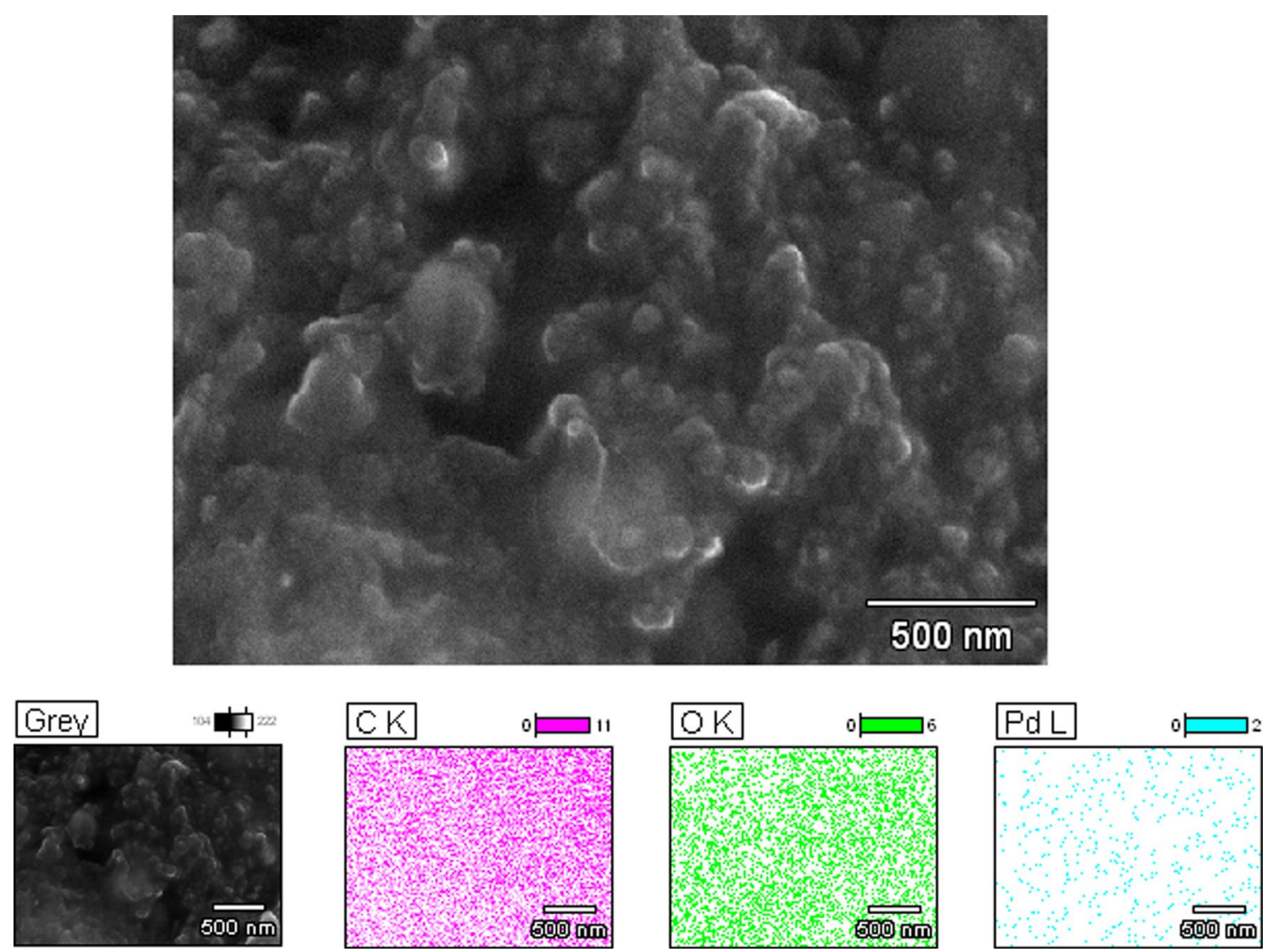

Fig. 8 SEM image and EDX analysis of Pd dispersion

\section{Characterization of Pd nanoparticles incorporated PAni films}

Successful coating of Pd nanoparticle dispersion onto PAni films was confirmed using SEM imaging (Fig. 9). EDX analysis was used to quantify Pd amount in samples. EDX also verified a decent distribution of Pd nanoparticles in PAni films by means of $6.46 \%$ in weight and $0.83 \%$ by atoms (Fig. 9).

When the sensor surface was analyzed by AFM, a homogeneous topographical distribution was observed at most positions with an exception of occasional larger smooth aggregates which could have resulted from polymer-metal complexes. The most prominent topographical feature was the even rough surface consisting of nanostructures $(\sim 125 \mathrm{~nm})$ arising from PAni film (Fig. 10).

\section{Impedance analysis for moisture}

According to the impedance data obtained, the PAni sensor exhibits capacitive behavior hence this sensor can be categorized as capacitive type humidity sensor (Fig. 11). PAni film shows the lowest impedance value, while Pd only sensor shows the highest impedance value due to the unavailability of appropriate conductive paths. In the case of PAni, exposure to the water vapor gets PAni protonated (acid base reaction) via an electron hopping assisted by a proton transfer mechanism that results an impedance drop [43, 54, 62, 63]. Meanwhile, Pd incorporated PAni film exhibits impedance in between. Addition of polymer containing Pd nanoparticle solution might be the reason for this observation. Also, the variation of impedance with humidity seems to be almost overlapped in frequencies over $10 \mathrm{MHz}$ range. However, there is a distinct variation, which can be observed in the range of 1-10 MHz.

In 1-10 $\mathrm{MHz}$ region, some variation of impedance with humidity can be seen in PAni film, however the respective variation was marginal in contrast to that of $\mathrm{Pd}$ incorporated PAni film. However, a clear dependence of impedance on frequency with a direct correlation can be 


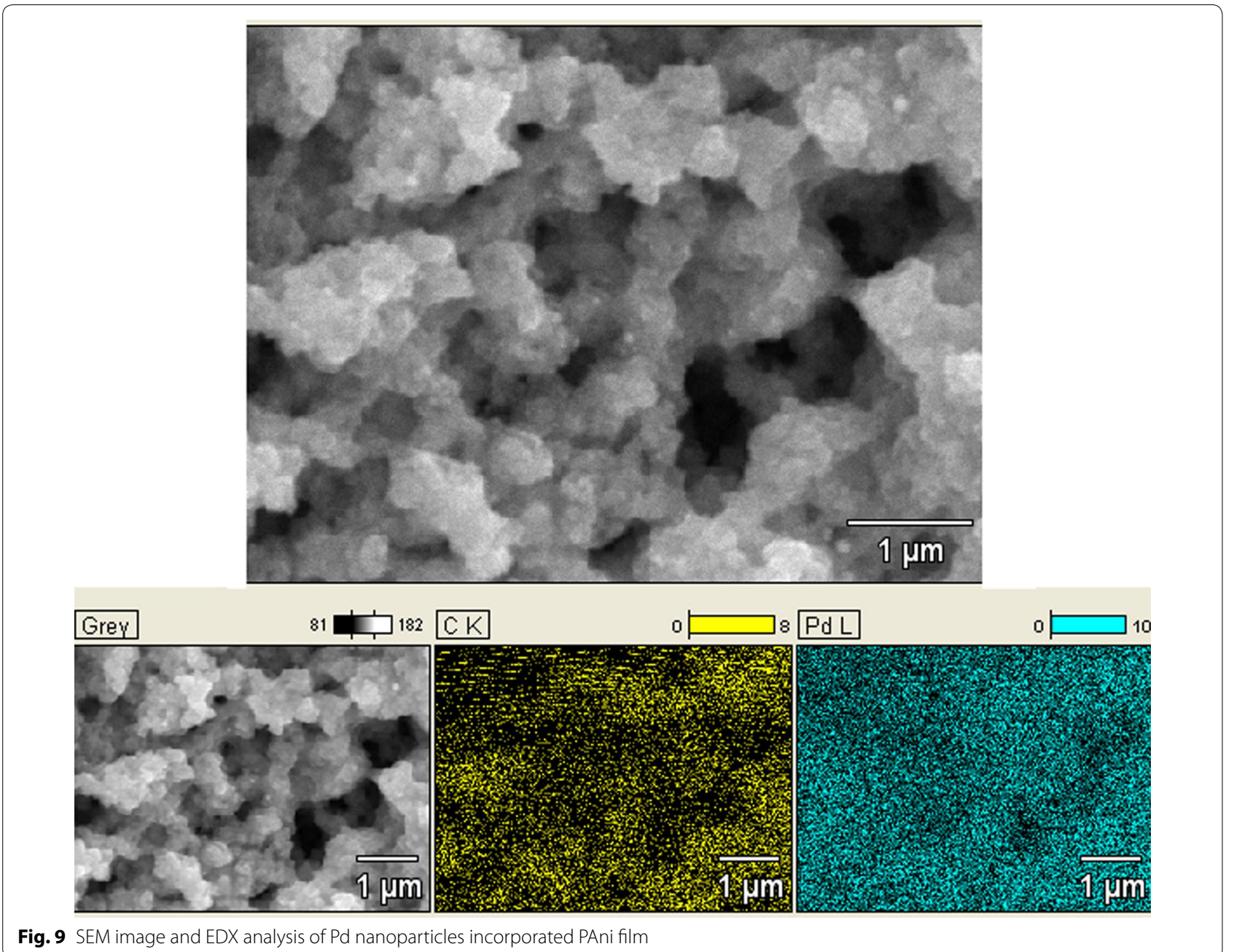

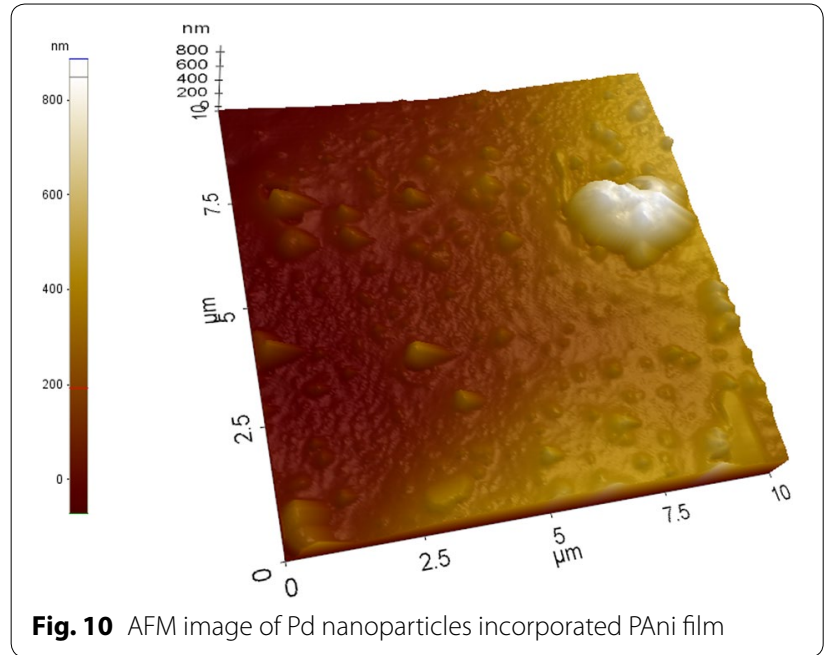

seen in Pd incorporated PAni film within the $1-10 \mathrm{MHz}$ region (Fig. 12).
According to the Fig. 12a, impedance decreased continuously with frequency under all humidity conditions. Also, the variation of impedance with humidity is distinguishable at the frequencies of 1 and $2 \mathrm{MHz}$. In both cases, the impedance at highest humidity $(97.3 \%)$ was less than half of the impedance at lowest humidity (32.8\%).

In Fig. 12b, relative humidity is plotted against impedance and it further justified the observation made before. Moreover, the figure indicated that the impedance variation at $1 \mathrm{MHz}$ was much superior and more linear $\left(R^{2}=0.97\right)$ implying that it is more suitable for sensor development in comparison to the sensitivity and linearity at $2 \mathrm{MHz}\left(\mathrm{R}^{2}=0.94\right)$ (Fig. 12c).

\section{Impedance analysis for $\mathrm{H}_{2}$}

Similar to the humidity sensing experiment, PAni films exhibit a capacitive behavior, hence the possible sensing element can be categorized as a capacitive type sensor. 

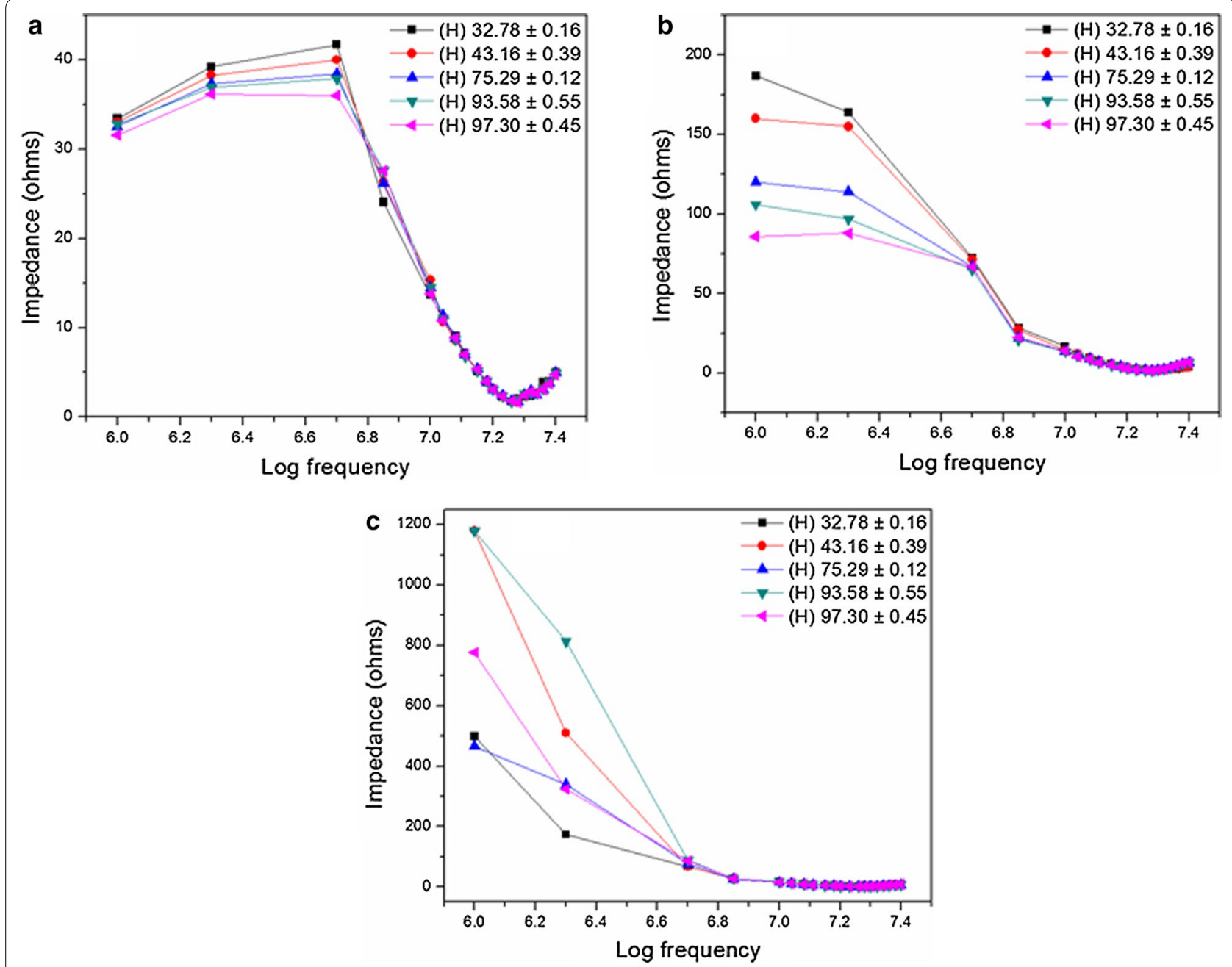

Fig. 11 Capacitive behavior of a PAni film, b Pd incorporated PAni film and $\mathbf{c}$ Pd only sensors for humidity

Interestingly, the impedance drop in Pd incorporated PAni film and Pd only film was distinguishable. However, it is hard to notice a visible correlation between impedance and frequency for PAni film (Fig. 13). Observations seem somewhat contradictory with some reported literature [64-66]. Presence of humidity in the $\mathrm{H}_{2}$ environment may be the reason for such a deviation [54]. Nevertheless, once PAni film was treated with Pd, a significant improvement in sensitivity for $\mathrm{H}_{2}$ was observed. Thus, Pd incorporated PAni film exhibited much superior performance towards $\mathrm{H}_{2}$ (Fig. 14).

Impedance drop with the elevation of $\mathrm{H}_{2}$ concentration and the frequency were clearly observed for Pd incorporated PAni film (Fig. 14). Results shown in Fig. 13b verified the previous observation and it further reveals that frequencies from 9 to $12 \mathrm{MHz}$ were well suited for quantifying the $\mathrm{H}_{2}$ levels, due to its steadiness in impedance drop where the regression analysis $\left(R^{2}\right)$ for linear curve fitting results over 0.90 for all frequencies. However, the sensitivity drop with the increasing frequency must also be taken into consideration in such an instance. Even though the impedance varied in a narrower range in presence of $\mathrm{H}_{2}$ at higher frequencies (13-15 MHz), a substantial variation in impedance was found as the sensor was exposed to the $\mathrm{H}_{2}$ gas. In detail, at $13 \mathrm{MHz}$, impedance decreased around $1 / 5$ th of its original value in the presence of $\mathrm{H}_{2}(11 \%)$, and it decreased less than half at both frequencies of $14 \mathrm{MHz}$ and $15 \mathrm{MHz}$ (Fig. 14b). Therefore, the Pd incorporated PAni film is well suited for the detection of $\mathrm{H}_{2}$ at 13-15 $\mathrm{MHz}$ frequency range.

Interestingly, Pd only also displays a substantial sensitivity towards $\mathrm{H}_{2}$. That is only possible due to the activity of Pd nanoparticles (Fig. 15).

Again, an impedance drop with frequency can be seen for Pd only film. Interestingly, a similar behavior was observed with the increment of $\mathrm{H}_{2}$ partial pressure at 

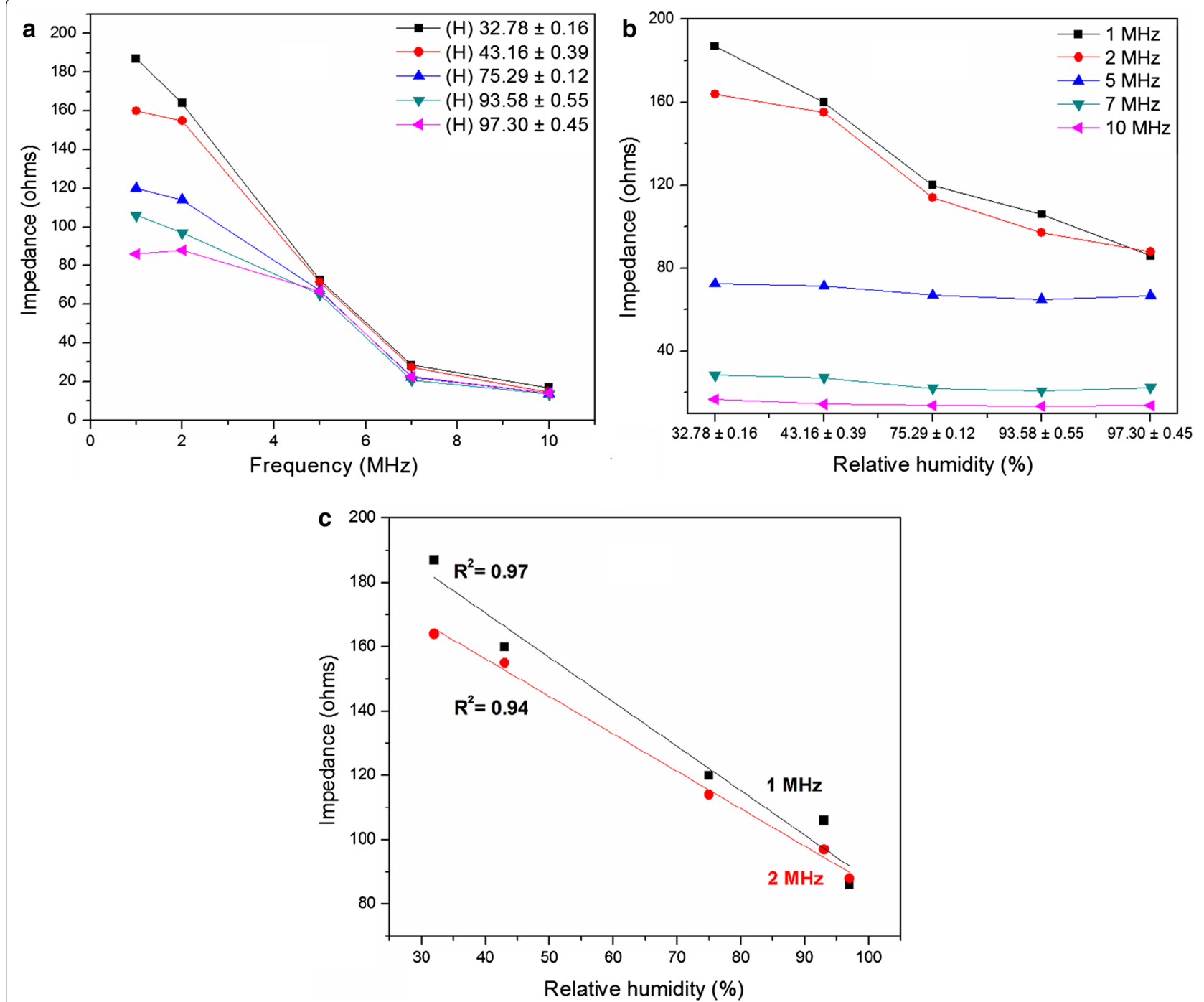

Fig. 12 a Impedance vs frequency, $\mathbf{b}$ impedance vs relative humidity in 1-10 MHz frequency domain for Pd incorporated PAni films and $\mathbf{c}$ linear curve fit at $1 \mathrm{MHz}$ and $2 \mathrm{MHz}$

lower frequencies (9-11 MHz) (Fig. 15). Unlike for Pd incorporated PAni film, $\mathrm{H}_{2}$ gas sensitivity is far minimal at other frequencies (Fig. 15b).

The results evidently revealed that $\mathrm{Pd}$ nanoparticles were the key component in detecting $\mathrm{H}_{2}$ gas. The capability of Pd to adsorb hydrogen and its ability to break $\mathrm{H}-\mathrm{H}$ bond may be the cause for the impedance drop in the presence of $\mathrm{H}_{2}[11,31]$. The enhancement of sensor performance inflicted by Pd nanoparticles incorporation into PAni film may be due to the possible spillover of $\mathrm{H}$ atoms (found from broken $\mathrm{H}-\mathrm{H}$ bond) towards the neighboring sites of PAni matrix that facilitates the proton transfer mechanism (earlier described under the "Impedance analysis for $\mathrm{H}_{2}$ " section) via its conducting pathways.

\section{Conclusions}

This study has shown that PAni is a suitable material for the detection of humidity. Incorporation of $\mathrm{Pd}$ to PAni increased the sensitivity for humidity. Importantly, PAni film alone did not exhibit $\mathrm{H}_{2}$ sensing properties. Hence, the presence of humidity in $\mathrm{H}_{2}$ might be the reason for such observations. Moreover, Pd only also exhibits hydrogen sensing activity and Pd incorporated PAni film shows significant sensing performances towards hydrogen. Fast and easy fabrication and cost-effectiveness would justify the candidacy of Pd incorporated PAni towards sensing both humidity and hydrogen. 

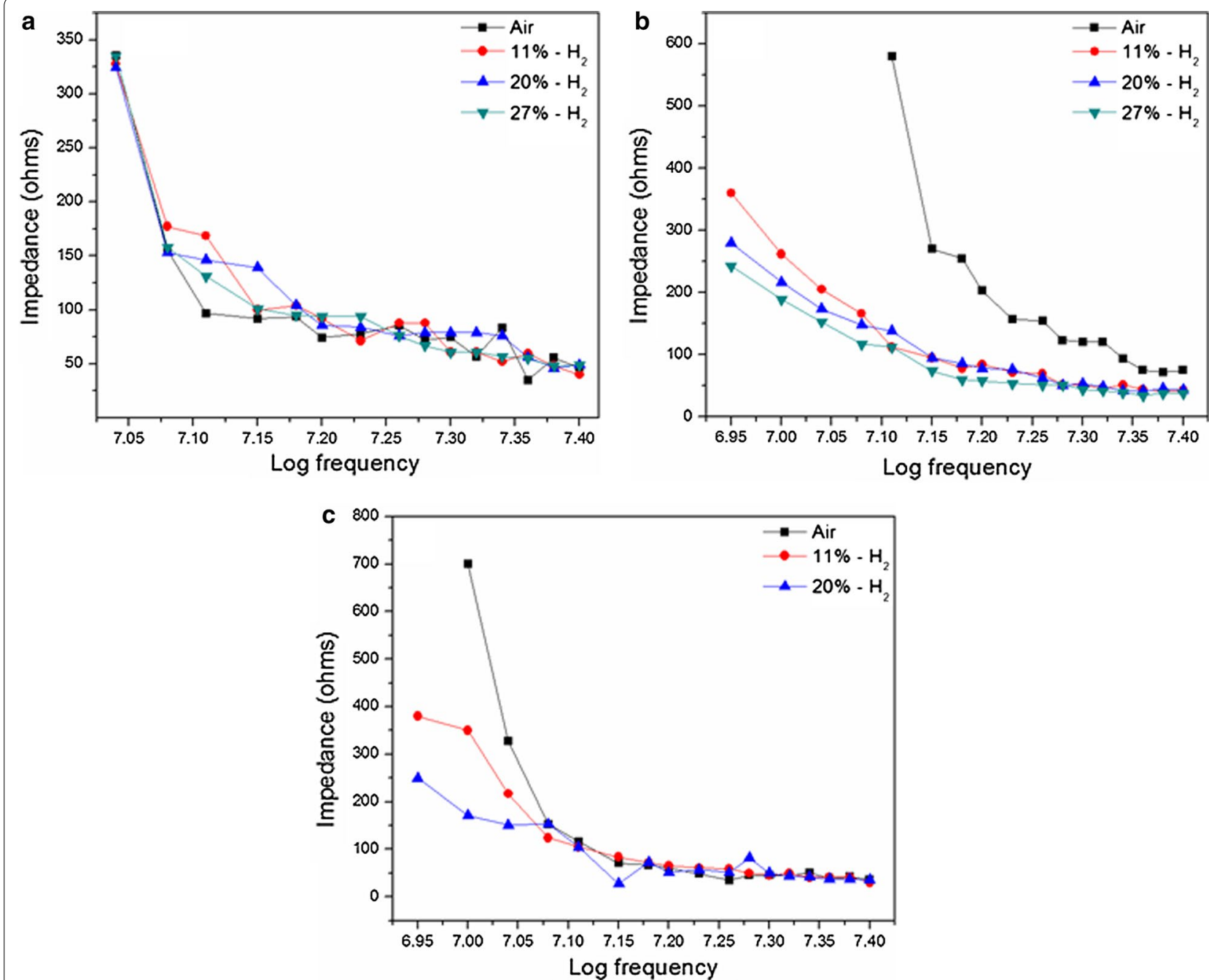

Fig. 13 Capacitive behavior of a PAni film, b Pd incorporated PAni film and $\mathbf{c}$ Pd only for $\mathrm{H}_{2}$ sensing
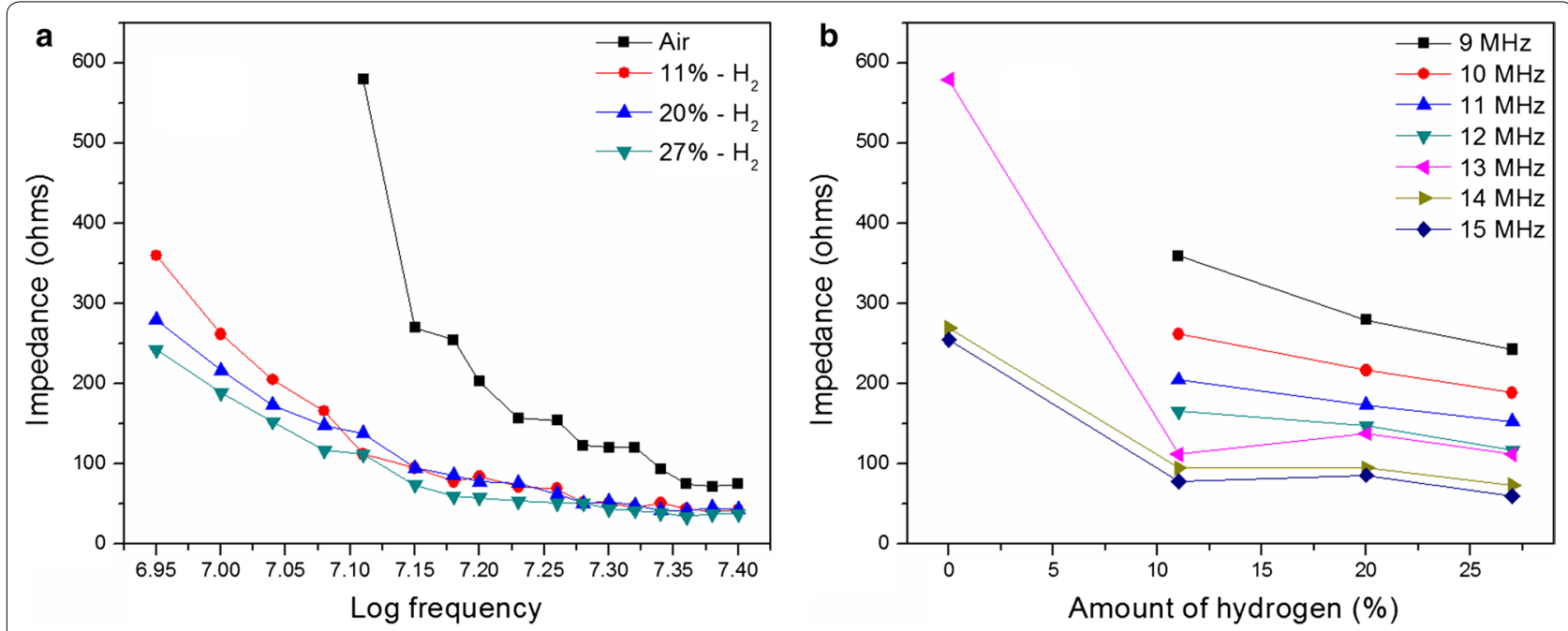

Fig. 14 a Impedance vs frequency and $\mathbf{b}$ impedance vs $\mathrm{H}_{2}$ percentage in 9-15 MHz frequency domain for Pd incorporated PAni films 

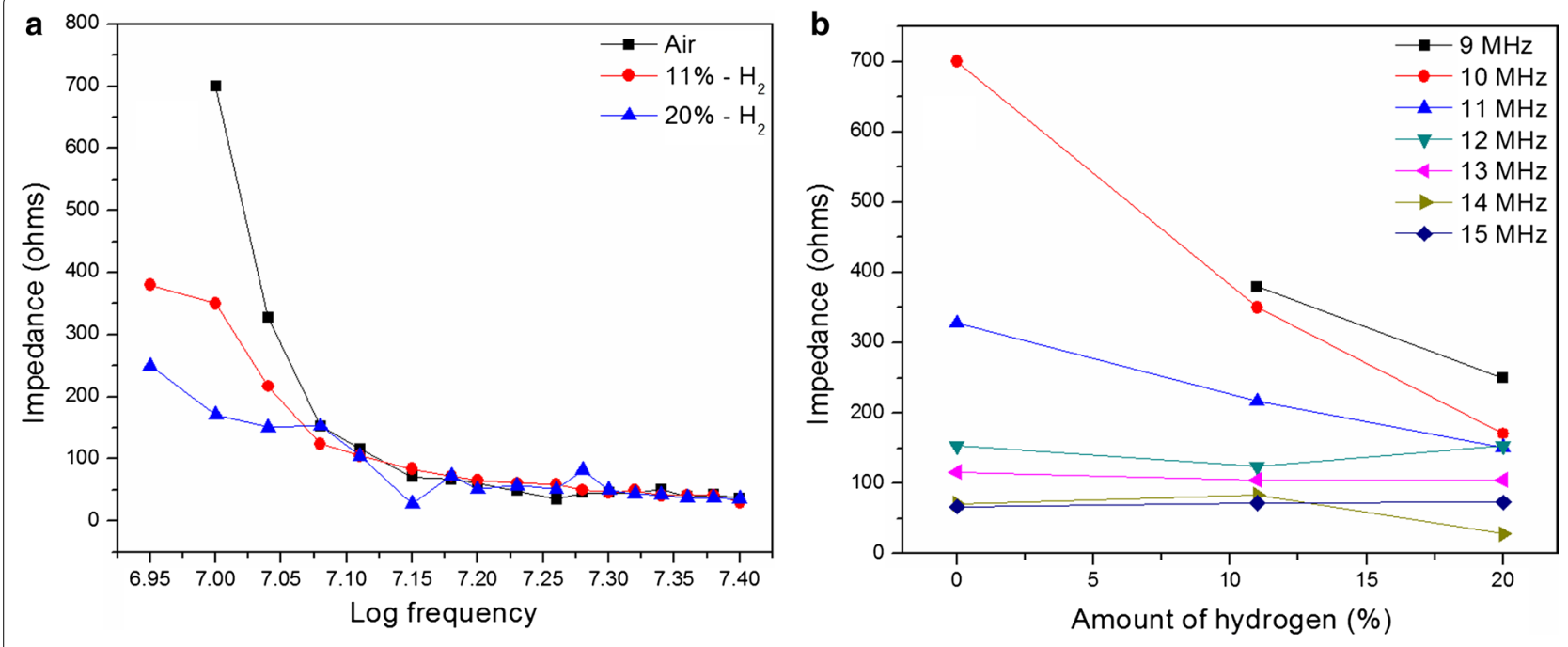

Fig. 15 a Impedance vs frequency and $\mathbf{b}$ impedance vs $\mathrm{H}_{2}$ percentage in 9-15 $\mathrm{MHz}$ frequency domain for Pd only film

\section{Abbreviations}

Pd NPs: palladium nanoparticles; D/F PT: dew/frost point; $\mathrm{RH}$ : relative humidity; PAni: polyaniline; ER: epoxy resin; PVP: poly (N-vinyl-2-pyrrolidone); PIPTF: Pd nanoparticles incorporated PAni thin films; PDI: polydispersion index; EDX energy dispersive $x$-ray; SEM: scanning electron microscopy; FT-IR: Fourier transform infra-red.

\section{Authors' contributions}

CS and DPD developed the concept and designed the project. CS and TSEFK performed laboratory experiments. CS, TSEFK, HMPCKH, and SR analyzed the data and participated in manuscript preparation. GAJA mentored the project and co-supervised the team. DPD supervised, and provided the leadership. All authors read and approved the final manuscript.

\section{Author details}

${ }^{1}$ Sri Lanka Institute of Nanotechnology (SLINTEC), Homagama, Sri Lanka. ${ }^{2}$ Department of Chemistry, University of Colombo, Colombo 3, Sri Lanka.

${ }^{3}$ Department of Engineering, University of Cambridge, Trumpington Street, Cambridge CB2 1PZ, UK

\section{Acknowledgements}

Authors wish to acknowledge Professor Nilwala Kottegoda, Dr. Asitha Siriwardhana, Sunanda Gunasekara, Damayanthi Dahanayake, Gayan Priyadarshana and Kosala Haputhanthri at Sri Lanka Institute of Nanotechnology and Dr. C. Dilrukshi Wijayarathna at the University of Colombo for their continuous support and Sri Lanka Institute of Nanotechnology for providing infrastructure for carrying out the research.

\section{Competing interests}

The authors declare that they have no competing interests.

\section{Consent for publication}

The datasets used and/or analyzed during the current study are available from the corresponding author on reasonable request.

\section{Ethics approval and consent to participate}

Not applicable.

\section{Funding}

Not applicable.

\section{Publisher's Note}

Springer Nature remains neutral with regard to jurisdictional claims in published maps and institutional affiliations.
Received: 13 February 2018 Accepted: 8 August 2018

Published online: 16 August 2018

\section{References}

1. Wang J, Kwak Y, Lee I-Y, Maeng S, Kim G-H (2012) Highly responsive hydrogen gas sensing by partially reduced graphite oxide thin films at room temperature. Carbon 50(11):4061-4067

2. Hoffmann P (2012) Tomorrow's energy: hydrogen, fuel cells, and the prospects for a cleaner planet. MIT press, Cambridge

3. Hübert T, Boon-Brett L, Black G, Banach U (2011) Hydrogen sensors-a review. Sens Actuators B Chem 157(2):329-352

4. Lapham D, Schwandt C, Hills M, Kumar R, Fray D (2002) The detection of hydrogen in molten aluminium. lonics 8(5-6):391-401

5. Schwandt C, Fray D (2000) Hydrogen sensing in molten aluminium using a commercial electrochemical sensor. Ionics 6(3-4):222-229

6. Sayago I, Terrado E, Lafuente E, Horrillo M, Maser W, Benito A et al (2005) Hydrogen sensors based on carbon nanotubes thin films. Synth Met 148(1):15-19

7. Chadwick B, Gal M (1993) Enhanced optical detection of hydrogen using the excitation of surface plasmons in palladium. Appl Surf Sci 68(1):135-138

8. Buttner WJ, Post MB, Burgess R, Rivkin C (2011) An overview of hydrogen safety sensors and requirements. Int J Hydrogen Energy 36(3):2462-2470

9. Luongo K, Sine A, Bhansali S (2005) Development of a highly sensitive porous Si-based hydrogen sensor using Pd nano-structures. Sens Actuators B Chem 111:125-129

10. Villatoro J, Monzón-Hernández D (2005) Fast detection of hydrogen with nano fiber tapers coated with ultra thin palladium layers. Opt Express 13(13):5087-5092

11. Adams BD, Chen A (2011) The role of palladium in a hydrogen economy Mater Today 14(6):282-289

12. Chen Z, Jie J, Luo L, Wang H, Lee CS, Lee ST (2007) Applications of silicon nanowires functionalized with palladium nanoparticles in hydrogen sensors. Nanotechnology 18(34):345502

13. Joshi RK, Krishnan S, Yoshimura M, Kumar A (2009) Pd nanoparticles and thin films for room temperature hydrogen sensor. Nanoscale Res Lett 4(10):1191-1196

14. Ju S, Lee JM, Jung Y, Lee E, Lee W, Kim S-J (2010) Highly sensitive hydrogen gas sensors using single-walled carbon nanotubes grafted with $\mathrm{Pd}$ nanoparticles. Sens Actuators B Chem 146(1):122-128 
15. Mubeen S, Zhang T, Yoo B, Deshusses MA, Myung NV (2007) Palladium nanoparticles decorated single-walled carbon nanotube hydrogen sensor. J Phys Chem C 111(17):6321-6327

16. Sun Y, Wang HH (2007) High-performance, flexible hydrogen sensors that use carbon nanotubes decorated with palladium nanoparticles. Adv Mater 19(19):2818-2823

17. Thomas PJ, Kulkarni G (2003) From colloids to nanotechnology: investigations on magic nuclearity palladium nanocrystals. Curr Sci 85(12):1760-1766

18. Corma A, Garcia H, Leyva A (2005) Catalytic activity of palladium supported on single wall carbon nanotubes compared to palladium supported on activated carbon: study of the Heck and Suzuki couplings, aerobic alcohol oxidation and selective hydrogenation. J Mol Catal A Chem 230(1-2):97-105

19. Demir MM, Gulgun MA, Menceloglu YZ, Erman B, Abramchuk SS, Makhaeva EE et al (2004) Palladium nanoparticles by electrospinning from poly (acrylonitrile-co-acrylic acid)- $\mathrm{PdCl} 2$ solutions. Relations between preparation conditions, particle size, and catalytic activity. Macromolecules 37(5):1787-1792

20. Yamauchi M, Ikeda R, Kitagawa H, Takata M (2008) Nanosize effects on hydrogen storage in palladium. J Phys Chem C 112(9):3294-3299

21. Astruc D (2007) Palladium nanoparticles as efficient green homogeneous and heterogeneous carbon-carbon coupling precatalysts: a unifying view. Inorg Chem 46(6):1884-1894

22. Li Y, Fan X, Qi J, Ji J, Wang S, Zhang G et al (2010) Palladium nanoparticlegraphene hybrids as active catalysts for the Suzuki reaction. Nano Research 3(6):429-437

23. Chen X, Wu G, Chen J, Chen X, Xie Z, Wang X (2011) Synthesis of "Clean" and well-dispersive Pd nanoparticles with excellent electrocatalytic property on graphene oxide. J Am Chem Soc 133(11):3693-3695

24. Mazumder V, Chi M, More KL, Sun S (2010) Core/shell Pd/FePt nanoparticles as an active and durable catalyst for the oxygen reduction reaction. J Am Chem Soc 132(23):7848-7849

25. Zhang F, Jin J, Zhong X, Li S, Niu J, Li R et al (2011) Pd immobilized on amine-functionalized magnetite nanoparticles: a novel and highly active catalyst for hydrogenation and Heck reactions. Green Chem 13(5):1238-1243

26. Bartczak WM, Stawowska J (2004) Interaction of dihydrogen with transition metal (Pd, Ni, Ag, Cu) clusters. Struct Chem 15(5):447-459

27. Cheon YE, Suh MP (2009) Enhanced hydrogen storage by palladium nanoparticles fabricated in a redox-active metal-organic framework. Angew Chem Int Ed 48(16):2899-2903

28. Vons VA, Leegwater H, Legerstee WJ, Eijt SWH, Schmidt-Ott A (2010) Hydrogen storage properties of spark generated palladium nanoparticles. Int J Hydrogen Energy 35(11):5479-5489

29. Singh P, Kulkarni MV, Gokhale SP, Chikkali SH, Kulkarni CV (2012) Enhancing the hydrogen storage capacity of Pd-functionalized multiwalled carbon nanotubes. Appl Surf Sci 258(8):3405-3409

30. Shi Z, Szpunar JA (2007) Synthesis of an ultra-thin palladium membrane for hydrogen extraction. Rev Adv Mater Sci 15:1-9

31. Yun S, Ted Oyama S (2011) Correlations in palladium membranes for hydrogen separation: a review. J Membr Sci 375(1):28-45

32. Chen Z, Lu C (2005) Humidity sensors: a review of materials and mechanisms. Sens Lett 3(4):274-295

33. Farahani $H$, Wagiran $R$, Hamidon MN (2014) Humidity sensors principle, mechanism, and fabrication technologies: a comprehensive review. Sensors 14(5):7881-7939

34. Traversa E (1995) Ceramic sensors for humidity detection: the state-of-the-art and future developments. Sens Actuators B Chem 23(2):135-156

35. Zeng F-W, Liu X-X, Diamond D, Lau KT (2010) Humidity sensors based on polyaniline nanofibres. Sens Actuators B Chem 143(2):530-534

36. Bracken E (1997) Combating humidity-the hidden enemy in manufacturing. Sens Rev 17(4):291-298

37. Ahonen T, Virrankoski R, Elmusrati M, editors. Greenhouse monitoring with wireless sensor network. In: Mechtronic and embedded systems and applications, 2008 MESA 2008 IEEE/ASME international conference on. 2008. IEEE

38. Roveti DK (2001) Choosing a humidity sensor: a review of three technologies this discussion of the operating principles of capacitive, resistive, and thermal conductivity humidity sensors also addresses their advantages, disadvantages, and applications. Sens J Appl Sens Technol 18(7):54-58

39. Rittersma ZM (2002) Recent achievements in miniaturised humidity sensors - a review of transduction techniques. Sens Actuators A 96(2-3):196-210

40. Ducéré $V$, Bernès $A$, Lacabanne C (2005) A capacitive humidity sensor using cross-linked cellulose acetate butyrate. Sens Actuators B Chem 106(1):331-334

41. Kang U, Wise KD (2000) A high-speed capacitive humidity sensor with on-chip thermal reset. IEEE Trans Electron Devices 47(4):702-710

42. Sakai Y, Matsuguchi M, Yonesato N (2001) Humidity sensor based on alkali salts of poly(2-acrylamido-2-methylpropane sulfonic acid). Electrochim Acta 46(10-11):1509-1514

43. Sakai Y, Sadaoka Y, Matsuguchi M (1996) Humidity sensors based on polymer thin films. Sens Actuators B Chem 35(1-3):85-90

44. Yang M-R, Chen K-S (1998) Humidity sensors using polyvinyl alcohol mixed with electrolytes. Sens Actuators B Chem 49(3):240-247

45. Hsueh H, Hsueh T, Chang S, Hung F, Tsai T, Weng W et al (2011) CuO nanowire-based humidity sensors prepared on glass substrate. Sens Actuators B Chem 156(2):906-911

46. Tao B, Zhang J, Miao F, Li H, Wan L, Wang Y (2009) Capacitive humidity sensors based on Ni/SiNWs nanocomposites. Sens Actuators B Chem 136(1):144-150

47. Harrey PM, Ramsey BJ, Evans PSA, Harrison DJ (2002) Capacitive-type humidity sensors fabricated using the offset lithographic printing process. Sens Actuators B Chem 87(2):226-232

48. Adhikari B, Majumdar S (2004) Polymers in sensor applications. Prog Polym Sci 29(7):699-766

49. Bai H, Shi G (2007) Gas sensors based on conducting polymers. Sensors 7(3):267-307

50. Connolly E, O'Halloran G, Pham H, Sarro P, French P (2002) Comparison of porous silicon, porous polysilicon and porous silicon carbide as materials for humidity sensing applications. Sens Actuators A 99(1):25-30

51. Goldberg HD, Brown RB, Liu DP, Meyerhoff ME (1994) Screen printing: a technology for the batch fabrication of integrated chemical-sensor arrays. Sens Actuators B Chem 21(3):171-183

52. Hulanicki A, Glab S, Ingman F (1991) Chemical sensors: definitions and classification. Pure Appl Chem 63(9):1247-1250

53. Nemamcha A, Rehspringer J-L, Khatmi D (2005) Synthesis of palladium nanoparticles by sonochemical reduction of palladium (II) nitrate in aqueous solution. J Phys Chem B 110(1):383-387

54. Herath $H$, Pradeep E, Jayananda M, Jayanetti J, Kapaklis V, Dissanayake D (2012) Glass surface functionalized with polyaniline as a fast responding humidity sensor. Sens Transducers 137(2):137-144

55. Molapo KM, Ndangili PM, Ajayi RF, Mbambisa G, Mailu SM, Njomo N et al (2012) Electronics of conjugated polymers (I): polyaniline. Int J Electrochem Sci 7(12):17

56. Gvozdenović MM, Jugović BZ, Stevanović JS, Trišović TL, Grgur BN (2011) Electrochemical polymerization of aniline. Electropolymerization 2011:77-96

57. Hasik M, Drelinkiewicz A, Wenda E, Paluszkiewicz C, Quillard S (2001) FTIR spectroscopic investigations of polyaniline derivatives-palladium systems. J Mol Struct 596(1-3):89-99

58. Yelil Arasi A, Juliet Latha Jeyakumari J, Sundaresan B, Dhanalakshmi V, Anbarasan R (2009) The structural properties of poly(aniline)-analysis via FTIR spectroscopy. Spectrochim Acta A Mol Biomol SpectrosC 74(5):1229-1234

59. Fujimoto T, Terauchi S-Y, Umehara H, Kojima I, Henderson W (2001) Sonochemical preparation of single-dispersion metal nanoparticles from metal salts. Chem Mater 13(3):1057-1060

60. Didillon B, Merlen E, Pages T, Uzio D (1998) From colloidal particles to supported catalysts: a comprehensive study of palladium oxide hydrosols deposited on alumina. Stud Surf Sci Catal 118:41-54

61. Cookson J (2012) The preparation of palladium nanoparticles. Platin Met Rev 56(2):83-98

62. Ogura K, Fujii A, Shiigi H, Nakayama M, Tonosaki T (2000) Effect of hygroscopicity of insulating unit of polymer composites on their response to relative humidity. J Electrochem Soc 147(3):1105-1109

63. Tissera ND, Wijesena RN, Rathnayake S, de Silva RM, de Silva KMN (2018) Heterogeneous in situ polymerization of polyaniline (PANI) nanofibers on 
cotton textiles: improved electrical conductivity, electrical switching, and tuning properties. Carbohyd Polym 186:35-44

64. Sadek A, Wlodarski W, Kalantar-Zadeh K, Baker C, Kaner R (2007) Doped and dedoped polyaniline nanofiber based conductometric hydrogen gas sensors. Sens Actuators A 139(1):53-57

65. Arsat R, Yu XF, Li YX, Wlodarski W, Kalantar-zadeh K (2009) Hydrogen gas sensor based on highly ordered polyaniline nanofibers. Sens Actuators B Chem 137(2):529-532
66. Fowler JD, Virji S, Kaner RB, Weiller BH (2009) Hydrogen detection by polyaniline nanofibers on gold and platinum electrodes. J Phys Chem C 113(16):6444-6449

\section{Submit your manuscript to a SpringerOpen ${ }^{\circ}$ journal and benefit from:}

- Convenient online submission

- Rigorous peer review

- Open access: articles freely available online

- High visibility within the field

- Retaining the copyright to your article

Submit your next manuscript at $\boldsymbol{\nabla}$ springeropen.com 